1. Jornalista e mestranda em Desenvolvimento Sustentável pela UnB. E-mail: cynthia.cpk@gmail. com

\title{
Ética, consumo e interdependência planetária
}

(ZYGMUNT BAUMAN. A Ética é possível num mundo de consumidores? Rio de Janeiro, Zahar, 2011. Traduzido do original em inglês Does Ethics have a chance in a world of consumers?, Londres 2008, Trad. Alexandre Werneck. )

Cynthia Sims ${ }^{1}$

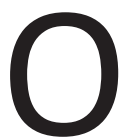
tema da modernidade líquida é a preocupação central da produção intelectual de Zygmunt Bauman. Ele é professor emérito de Sociologia das Universidades de Leeds, Grã-Bretanha, onde lecionou por vinte anos, e de Varsóvia, onde iniciou a sua carreira e foi afastado em 1968. Tem dezenas de livros publicados em diversas línguas, sendo Modernidade Líquida, Modernidade e Holocausto e $O$ mal-estar da pós-modernidade os mais conhecidos. No Brasil, 28 títulos de sua autoria foram publicados pela Zahar Editora.

O texto original de $A$ Ética é possível num mundo de consumidores? foi lançado em Londres, em 2008, mas a sua edição brasileira é de 2011. É o resultado de uma série de conferências que o autor proferiu na Universidade de Viena. Da mesma forma que em obras anteriores, Bauman constrói a sua argumentação contrapondo as características de dois momentos da modernidade: o advento simultâneo das Revoluções e da consolidação dos Estados-nação com o momento presente, o que ele chama de modernidade líquida, demarcado a partir do período pós-guerra e intensificado pelos processos de globalização econômica e expansão da Internet na década de 1990. O autor examina as implicações dessa nova condição moderna para questões da esfera pública, como a ética, o mercado e a democracia; e da esfera privada, como as decisões do consumo e as relações amorosas.

Na modernidade líquida, a sujeição às regras sociais dá-se no espaço de tensão entre o anseio de liberdade do indivíduo e a busca pela segurança, que só a aprovação social permite. A afirmação do indivíduo requer o artifício do pertencimento, que é resultado das mais estranhas combinações entre coletivos: "a população de qualquer país hoje é uma coleção de diásporas" (p. 15). Ao mesmo tempo, não há espaço exterior à globalização. Os coletivos não estão mais circunscritos a territórios específicos, mas habitam o "espaço de fluxos" (Manuel Castells). 
O ensaio que dá nome ao livro inicia pela contradição entre o preceito do amor ao próximo e a busca moderna pela satisfação individual. O Mal Estar da Civilização, de Freud, inspira o autor a refletir sobre essa ambivalência: de um lado, o indivíduo expressa o respeito à singularidade e, do lado mais obscuro, a desconfiança de que o próximo seja uma ameaça. Tal desconfiança é nomeada como ressentimento por Friedrich Nietszche e Max Scheler. Bauman acrescenta um novo ressentimento característico dos tempos líquidos modernos: o que nos impele contra pessoas estranhas, porque representam a impermanência, é fruto dos efeitos negativos da globalização, que produzem o que o autor chama de "refugos humanos da fronteira global" (p. 45). Contudo, tomar as vítimas da globalização por ameaças à segurança é um artifício adequado para fechar-lhes as portas e dificultar ainda mais a governança mundial.

Bauman aborda o tema do Holocausto sob a forma de assassinato categórico de pessoas marcadas pela sua atribuição de uma categoria considerada imprópria para a ordem planejada. No século XX, não apenas os judeus, mas inúmeros grupos étnicos foram considerados pessoas erradas nos lugares errados. Os reflexos dessa história recente na sociedade líquida global apresentam-se sob a forma de competição, violência e hostilidades recíprocas, que, virtualmente, só acabariam com o extermínio completo de um dos grupos. Esses conflitos alcançam dimensões planetárias: um sistema financeiro global e instável; refugiados ambientais e imigrantes por toda parte; dificuldades de gestão dos bens comuns. O autor exorta à solidariedade e à convergência de esforços para constituir uma nova governança global, sem a qual os grandes coletivos - nações, etnias, classes sociais - podem estar fadados a se destruir mutuamente.

Em grandes grupos, nos quais as mediações prevalecem sobre as relações face a face, o senso moral tem de ser reprocessado sob a forma de contrato social. Mas a modernidade líquida solapa os argumentos de um contrato social altruísta (Rousseau) ou coercitivo (Hobbes). Uma nova coerção, mais sutil, deixa o peso das escolhas sobre os ombros dos consumidores, na falta de uma governança eficiente - um novo contrato social? - que determine os limites éticos da economia de mercado.

A grande contribuição da Modernidade, para o autor, seria o pensar autônomo do sujeito esclarecido. Dessa autonomia, deveria emergir um contrato social de Homens livres e iguais numa sociedade fraterna, na qual fosse assegurado a cada um o direito de buscar a sua felicidade. Contudo, nossa liberdade pessoal não é nada pertinente às regras do jogo no mundo líquido em que vivemos.

Os grandes eventos, como a Copa do Mundo e o Carnaval, são bons exemplos de "festivais de integração comunal e pertencimento" (p. 160), aos quais os indivíduos entregam-se disciplinadamente, pois o conforto do enxame vem da segurança 
do número: tanta gente na mesma direção não pode estar errada. Precisam da sensação de pertencimento a um coletivo em função do produto comprado,mas não suportam a efemeridade da satisfação de uma "necessidade" que logo será suplantada por um novo estímulo ao consumo. Tem-se a ilusão de liberdade de escolha dentre opções que, contudo, são pré-definidas e inegociáveis. É a falácia da satisfação - sempre perseguida no processo de compra, e sempre adiada para a próxima promessa - que move os consumidores e dinamiza a economia.

A consequência do consumo desenfreado é o intenso descarte dos produtos ultrapassados. É assim que Bauman analisa a obsolescência programada e o excesso de informação a que estão sujeitos os indivíduos da modernidade líquida. Para ele, há cada vez mais evidências de que mais renda não corresponde a mais felicidade e de que ela pode até contribuir para menos confiança e mais conflito nas sociedades abastadas.

O tempo líquido moderno é pontilhista, fragmentado per se. Cada instante tem o mesmo potencial e a mesma insignificância de todos os demais. Uma vida assim, no tempo instantâneo, exige habilidades de bricoleur, de um prestidigitador que transfere para o consumo a costura de sua identidade e a pretensão de conquistar alguma felicidade instrumental. Aos que não desenvolvem tais habilidades, resta a eliminação do jogo, como consumidores falhos, perdedores.

As artes também refletem a permanente tensão entre os artistas e os produtores culturais. O gerenciamento dos bens culturais deslocou-se da antiga estratégia de censura para a nova estratégia de sedução, que define critérios de mercado (consumo imediato e lucro) para legitimar as criações culturais. Aos artistas, resta a opção entre o exílio e a submissão à ordem. O efeito de tal mudança na sociedade de consumo é a fragilização das rotinas - tudo está fadado a perecer, e cada vez mais rápido - e a acentuação do individualismo leva à alienação da esfera pública.

A instantaneidade é parte do jogo, indispensável ao estilo de vida-para-consumo que é recomendado e amplamente aceito sob o disfarce de liberdade. Viver nessa versão líquida moderna é uma promessa de liberdade, cujo cumprimento, no final das contas, é escasso e seletivo (p. 144). Quem pode assegurar a liberdade individual é o Estado social que, pela proteção social garantida a todos, defende os consumidores contra a exclusão e, assim, permite o exercício democrático e a solidariedade.

No último capítulo, o autor volta-se para a reflexão sobre a situação da Europa, que lamenta a perda de sua centralidade nas relações com outros povos, hoje mais absortos em seus próprios problemas e ressentidos da histórica predação de seus recursos que viabilizou o padrão europeu de 
civilização. Depois de quinhentos anos de domínio econômico e militar do mundo, os europeus conseguirama proeza de criar problemas locais em seu continente e solucioná-los habilmente com recursos globais, espoliando os demais, transformando-os em fontes de energia e recursos naturais de baixo custo; e em áreas de descarte para os produtos excedentes e as pessoas insignificantes que estivessem incomodando o velho continente.

Bauman, então, lembra da reflexão de Immanuel Kant sobre a forma esférica do planeta, que torna todos os povos vizinhos e deveria conduzi-los a uma hospitalidade natural de cidadãos planetários. Para o autor, o papel do continente europeu nesse cenário instável poderia ser a liderança no processo de uma nova democracia planetária que proporcionasse a convivência pacífica entre diferentes grupos étnicos. Por suas dimensões espaciais e por sua história, os europeus souberam articular a criação dos Estados-nação mediante alianças entre diferentes grupos - ele cita os exemplos da Alemanha, formada por bávaros e prussianos; e da França, de sabourianos e bretões. Assim, a forma de democracia inventada na Europa ensina que um Estado forte consegue garantir a integração social por meio da ampla participação política.

Um sociólogo que analise a ética necessariamente reporta-se à Filosofia. Algumas influências são referenciadas pelo próprio Bauman em diversos artigos, como Freud, Adorno, Arendt, Habermas, Levinas, Simmel. Mas, depois de trazer os seus argumentos filosóficos mais abstratos, Bauman sempre os mergulha no cotidiano da sociedade de consumo. Ética, para ele, relaciona-se às decisões que cada consumidor deve tomar corriqueiramente, pois elas espelham as regras do jogo, que estão além do alcance de cada um em particular. Fragmentados num mundo líquido consumista, sem uma governança global que regule os mecanismos de mercado, os indivíduos deparam-se com a alteridade por meio de identidades fluidas em constante transformação; enxergam nela a sua própria fragilidade e impotência, os seus ressentimentos, e a interdependência que reclama nossa responsabilidade em todas as escalas, do indivíduo ao mundo. Para Bauman, as decisões individuais de consumo não são triviais; coadunam-se com as responsabilidades planetárias, no grau extremo do lema "pensar globalmente, agir localmente".

Embora não seja propriamente um livro sobre questões ambientais, a reflexão de Bauman é bastante pertinente ao exame dos pressupostos da sociedade de consumo que, hoje global, determina o volume de extração dos recursos naturais. O livro é uma coletânea de conferências, o que pode soar repetitivo para os leitores habituais do autor, mas é um bom ponto de partida para os que desejam um primeiro contato com a extensa obra de Bauman, já que referencia vários de seus livros. Além disso, ele passeia por clássicos da Filosofia e das Ciências Sociais do século XX e aborda temas socioambientais, como a in- 
terdependência e os refugiados, lançando uma nova luz sobre os impactos do consumo na gestão dos commons, que não pode mais ser pensada ou solucionada sem recorrer a uma profunda revisão da ética em um mundo globalizado. 